Check for updates

Cite this: Chem. Sci., 2019, 10, 10122

๑ All publication charges for this article have been paid for by the Royal Society of Chemistry

\section{Core-dependent properties of copper nanoclusters: valence-pure nanoclusters as NIR TADF emitters and mixed-valence ones as semiconductors $\uparrow$}

\author{
Leon Li-Min Zhang, $\$^{\mathrm{a}}$ Guodong Zhou, (D) $\ddagger^{\mathrm{b}}$ Guoging Zhou, ${ }^{\mathrm{c}}$ Hung-Kay Lee, ${ }^{a}$ \\ Ni Zhao, (iD b Oleg V. Prezhdo (iD c and Thomas C. W. Mak (iD *a
}

\begin{abstract}
We report herein that copper alkynyl nanoclusters show metal-core dependent properties via a chargetransfer mechanism, which enables new understanding of their structure-property relationship. Initially, nanoclusters 1 and 2 bearing respective $\mathrm{Cu}\left(\mathrm{I}_{15}(\mathrm{C} 1)\right.$ and $\mathrm{Cu}\left(\mathrm{I}_{28}(\mathrm{C} 2)\right.$ cores were prepared and revealed to display near-infrared (NIR) photoluminescence mainly from the mixed alkynyl $\rightarrow \mathrm{Cu}(\mathrm{I})$ ligand-to-metal charge transfer (LMCT) and cluster-centered transition, and they further exhibit thermally activated delayed fluorescence (TADF). Subsequently, a vanadate-induced oxidative approach to in situ generate a nucleating $\mathrm{Cu}(\Perp)$ cation led to assembly of 3 and 4 featuring respective $\left[\mathrm{Cu}(\Perp) \mathrm{O}_{6}\right]\left(\mathrm{Cu}\left(\mathrm{I}_{47}(\mathrm{C} 3)\right.\right.$ and $\left\{\left[\mathrm{Cu}(॥) \mathrm{O}_{4}\right] \cdot\left[\mathrm{VO}_{4}\right]_{2}\right\} @ \mathrm{CC}\left({ }_{1}\right)_{46}(\mathrm{C} 4)$ cores. While interstitial occupancy of $\mathrm{Cu}(॥)$ triggers inter-valence chargetransfer (IVCT) from $\mathrm{Cu}(\mathrm{I})$ to $\mathrm{Cu}(\|)$ to quench the photoluminescence of 3 and 4 , such a process facilitates charge mobility to render them semiconductive. Overall, metal-core modification results in an interplay between charge-transfer processes to switch TADF to semiconductivity, which underpins an unusual structure-property correlation for designed synthesis of metal nanoclusters with unique properties and functions.
\end{abstract}

\author{
Received 12th July 2019 \\ Accepted 6th September 2019 \\ DOI: $10.1039 / c 9 s c 03455 b$ \\ rsc.li/chemical-science
}

\section{Introduction}

Amid rapid expansion of research endeavor into nanoscale materials, atomically precise metal nanoclusters have attracted considerable interest. ${ }^{1}$ They not only motivate continuous efforts in the chemical community to achieve ever-evolving compositional and structural complexity, but also serve as an inspiration to materials scientists due to their use in a variety of emerging technological applications. ${ }^{2}$ In particular, their precise structural nature facilitates deeper understanding of the structure-property relationship, which has direct ramifications for design of functional nanomaterials. ${ }^{3,4}$

In this regard, the copper alkynyl nanoclusters constitute a good research platform owing to their versatile self-assembled

\footnotetext{
${ }^{a}$ Department of Chemistry and Center of Novel Functional Molecules, The Chinese University of Hong Kong, Hong Kong SAR, People's Republic of China. E-mail: tcwmak@cuhk.edu.hk

${ }^{b}$ Department of Electronic Engineering, The Chinese University of Hong Kong, Hong Kong SAR, People's Republic of China

'Department of Chemistry, University of Southern California, Los Angeles, California 90089-1062, USA

$\dagger$ Electronic supplementary information (ESI) available. CCDC 1907665-1907669 and 1907707. For ESI and crystallographic data in CIF or other electronic format see DOI: $10.1039 / \mathrm{c} 9 \mathrm{sc} 03455 \mathrm{~b}$

$\ddagger$ These authors contributed equally to this work.
}

nanostructures and appealing physio-chemical properties in photoluminescence, catalysis, biomedical sensing and electronics. ${ }^{5}$ However, such a goal is currently far from reach. For example, while it is presumed that copper alkynyl nanoclusters would exhibit exotic photoluminescence performances, relevant investigations are very preliminary, and key studies are still mechanistic in nature. ${ }^{5}$ Nevertheless, some impressive progress has been made in the recent literature. Scott and Hayton reported $\left[\mathrm{Cu}_{20}(\mathrm{PhC} \equiv \mathrm{C})_{12}(\mathrm{OAc})_{6}\right]$ as an effective catalyst for $[3+2]$ cycloadditions between alkynes and azides. ${ }^{6}$ Zheng reported that $\left[\mathrm{Cu}_{53}\left(\mathrm{CF}_{3} \mathrm{COO}\right)_{10}\left({ }^{t} \mathrm{BuC} \equiv \mathrm{C}\right)_{20} \mathrm{Cl}_{2} \mathrm{H}_{18}\right]^{+}$was used as an effective precursor to generate $\gamma$-CuI films as perovskite solar cells. ${ }^{7}$ These results imply the potentiality of diversified yet underexplored attributes of copper alkynyl nanoclusters.

We have previously established a comproportionation reaction methodology and focused on the structural role of anionic species to enhance the size and nuclearity of copper(I) alkynyl nanoclusters. ${ }^{8}$ In this work, we make inroads to comparative synthesis of valence-pure and mixed-valence copper nanoclusters that exhibit metal-core dependent material properties via a charge-transfer mechanism, which enables new understanding of their structure-property relationship.

Initially, the comproportionation reaction furnished nanoclusters $\left[\mathrm{Cu}(\mathrm{I})_{15}\left({ }^{t} \mathrm{BuC} \equiv \mathrm{C}\right)_{14} \mathrm{NO}_{3}\right](\mathbf{1})$ and $\left[\mathrm{Cu}(\mathrm{I})_{28}\left({ }^{t} \mathrm{BuC} \equiv \mathrm{C}\right)_{22}(-\right.$ $\left.\left.\mathrm{SO}_{4}\right)_{2}(\mathrm{OMe})_{2}\right]$ (2). They were revealed to exhibit NIR 
photoluminescence mainly from the mixed alkynyl $\rightarrow \mathrm{Cu}(\mathrm{I})$ LMCT and cluster-centered transition and further exhibit TADF. To the best of our knowledge, 1 and 2 constitute the first examples of coinage-metal nanoclusters displaying NIR TADF. Subsequently, a vanadate-assisted approach to in situ generate a nucleating $\mathrm{Cu}$ (II) cation was developed in conjugation with the comproportionation reaction to assemble $\left\{\left[\mathrm{Cu}(\mathrm{II}) \mathrm{O}_{6}\right] @ \mathrm{Cu}(\mathrm{I})_{47}(-\right.$ $\left.\left.{ }^{i} \mathrm{PrC} \equiv \mathrm{C}\right)_{33}\right\}\left(\mathrm{ClO}_{4}\right)_{4} \quad$ (3) and $\left\{\left[\mathrm{Cu}(\mathrm{II}) \mathrm{O}_{4}\right]\left[\mathrm{VO}_{4}\right]_{2} @ \mathrm{Cu}(\mathrm{I})_{46}\right.$ $\left.\left({ }^{t} \mathrm{BuC} \equiv \mathrm{C}\right)_{27}\left({ }^{t} \mathrm{BuPO}_{3}\right)_{2}\left(\mathrm{H}_{2} \mathrm{O}\right)\right\}\left(\mathrm{BF}_{4}\right)_{3}\left(\mathrm{CH}_{2} \mathrm{Cl}_{2}\right)_{2}\left(\mathrm{Et}_{2} \mathrm{O}\right)_{2}\left(\mathrm{H}_{2} \mathrm{O}\right)$ While interstitial incorporation of $\mathrm{Cu}$ (II) triggers IVCT from $\mathrm{Cu}$ (I) to $\mathrm{Cu}$ (II) to quench the photoluminescence of $\mathbf{3}$ and $\mathbf{4}$, such a process facilitates charge mobility to render them semiconductive. Overall, metal-core modification originating from the interplay of the charge-transfer process causes a switch from TADF to semiconductivity. Such pros and cons effect of $\mathrm{Cu}$ (II) cations on cluster properties not only advances our knowledge on the structure-property relationship of atomically precise metal nanoclutructursters, but also provides a potential route to tailor future development of function-specific nanoclusters.

\section{Results and discussion}

\section{Synthesis and characterization}

While the structures of nanoclusters dictate their physiochemical behavior, ${ }^{9}$ a systematic synthetic study based on a proven methodology is not just a routine exercise, but it aims to obtain novel nanoclusters with desirable properties. Herein, screening the $\mathrm{Cu}$ (II) source of the comproportionation reaction $\mathrm{Cu}(0) / \mathrm{Cu}(\mathrm{II}) /{ }^{t} \mathrm{BuC} \equiv \mathrm{CH}$ furnished two valence-pure $\mathrm{Cu}(\mathrm{I})$ nanoclusters (Scheme 1, upper part). Use of $\mathrm{Cu}(\mathrm{II})\left(\mathrm{NO}_{3}\right)_{2}$ at room temperature yielded red crystals of $\left[\mathrm{Cu}(\mathrm{I}){ }_{15}\left({ }^{t} \mathrm{BuC} \equiv \mathrm{C}\right)_{14} \mathrm{NO}_{3}\right](\mathbf{1})$.

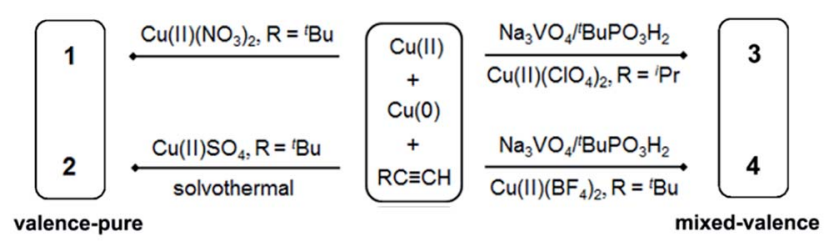

i) $20 \mathrm{Na}_{3} \mathrm{VO}_{4}+30 \mathrm{BuPO}_{3} \mathrm{H}_{2}=\left[\mathrm{V}_{10} \mathrm{O}_{28}\right]_{2} \cdot\left[\mathrm{H}_{3} \mathrm{O}\right]_{12}+30 \mathrm{Na}_{2}{ }^{\mathrm{B}} \mathrm{BuPO}_{3}+12 \mathrm{H}_{2} \mathrm{O}$

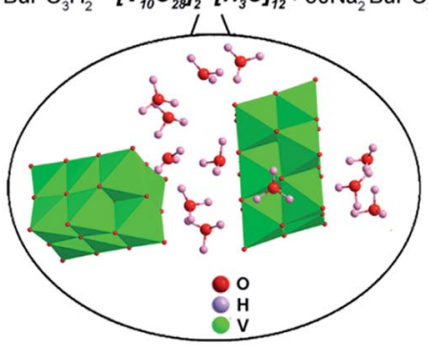

ii) $\mathrm{Cu}(0) \stackrel{\left[\mathrm{V}_{10} \mathrm{O}_{28}\right]_{2} \cdot\left[\mathrm{H}_{3} \mathrm{O}\right]_{12}}{\text { oxidation }} \mathrm{Cu}(\mathrm{II})$

Scheme 1 Upper: synthetic routes of copper nanoclusters 1-4. Lower: the vanadate-induced formation pathway of the nucleating $\mathrm{Cu}(\mathrm{II})$ cation in 3 and 4.
During revision of this manuscript, synthesis of $\mathbf{1}$ was reported by Xie and Lu. ${ }^{\mathbf{1 0}}$ Single-crystal X-ray diffraction analysis (SCXD) revealed that the $\mathrm{Cu}(\mathrm{I})_{15}$ (C1) core of $\mathbf{1}$ is stabilized by 14 alkynyl ligands and one $\mu-\kappa \mathrm{O}: \kappa \mathrm{O}^{\prime} \mathrm{NO}_{3}{ }^{-}$with $\mathrm{Cu}(\mathrm{I})-\mathrm{O}$ bond lengths of 2.169 and $2.379 \AA$ (Fig. 1a). By using $\mathrm{Cu}(\mathrm{II}) \mathrm{SO}_{4}$ in the solvothermal reaction, $\left[\mathrm{Cu}(\mathrm{I})_{28}\left({ }^{t} \mathrm{BuC} \equiv \mathrm{C}\right)_{22}\left(\mathrm{SO}_{4}\right)_{2}(\mathrm{OMe})_{2}\right]$ (2) was obtained as yellow crystals. Notably, 2 cannot be obtained without solvothermal treatment, presumably because its formation involving deprotonation of $\mathrm{MeOH}$ to the $\mathrm{MeO}^{-}$ bridging ligand does not readily occur under ambient conditions. As shown in Fig. 1b, in addition to 22 alkynyl ligands, two $\mu_{3}-\mathrm{MeO}^{-}$and two $\mu_{3}-\kappa \mathrm{O}: \kappa \mathrm{O}^{\prime}: \kappa \mathrm{O}^{\prime \prime} \mathrm{SO}_{4}{ }^{2-}$ ligands cap the respective central and terminal section of the $\mathrm{Cu}(\mathrm{I})_{28}$ (C2) core to assemble 2 as an elongated nanorod. In addition to its significant structural diversity, 2 also represents the highest-nuclearity $\mathrm{Cu}(\mathrm{I})$ alkynyl cluster assembled without an interstitial species. ${ }^{5 d}$ The $\mathrm{Cu}(\mathrm{I})-\mathrm{O}$ bond distances span the range 1.925-2.140 А.

Based on the comproportionation reaction to form $\mathrm{Cu}(\mathrm{I})$ nanoclusters, we have previously introduced polyoxomolybdate (POMo) to synthesize POMo@Cu(I) nanoclusters. ${ }^{8 a}$ Herein, an attempt to introduce polyoxovanadate (POV) ${ }^{11}$ by using $\mathrm{Na}_{3}$ $\mathrm{VO}_{4} /{ }^{t} \mathrm{BuPO}_{3} \mathrm{H}_{2}$ yielded unprecedented $\mathrm{Cu}(\mathrm{II})$-containing $\mathrm{Cu}(\mathrm{I})$ nanoclusters 3 and $\mathbf{4}$ (Scheme 1, upper part). Control experiments were conducted to probe the formation path for the $\mathrm{Cu}$ (II) cation. As illustrated in the lower part of Scheme 1, in step (i) $\mathrm{Na}_{3} \mathrm{VO}_{4} /{ }^{t} \mathrm{BuPO}_{3} \mathrm{H}_{2}$ reacted to form a decavanadate hydronium compound $\left[\mathrm{V}_{10} \mathrm{O}_{28}\right]_{2} \cdot\left[\mathrm{H}_{3} \mathrm{O}\right]_{12}$, which has not been reported prior to this work; in step (ii) $\left[\mathrm{V}_{10} \mathrm{O}_{28}\right]_{2} \cdot\left[\mathrm{H}_{3} \mathrm{O}\right]_{12}$ oxidized $\mathrm{Cu}(0)$ to in situ generate $\mathrm{Cu}$ (II) (see details in the ESI $\dagger$ ). The $\mathrm{Cu}$ (II) generated via such a POV-assisted route consequently serves as a nucleating cation to form the mixed-valence nanoclusters 3 and 4 .

In the synthesis of 3, a one-pot reaction of $\mathrm{Na}_{3} \mathrm{VO}_{4} /{ }^{t} \mathrm{BuPO}_{3} \mathrm{H}_{2}$ and $\mathrm{Cu}(0) / \mathrm{Cu}(\mathrm{II})\left(\mathrm{ClO}_{4}\right)_{2} /{ }^{i} \mathrm{PrC} \equiv \mathrm{CH}$ in methanol yielded a yellow precipitate that was re-dissolved in dichloromethane, to which
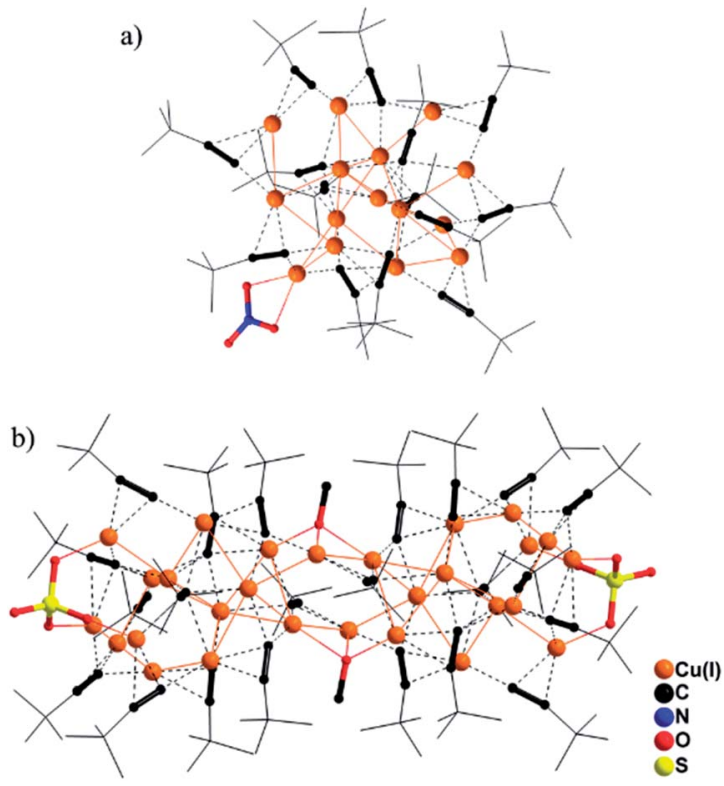

Fig. 1 Molecular structures of (a) 1; (b) 2. 
slow diffusion of diethyl ether afforded deep red crystals of $\left\{\left[\mathrm{Cu}(\mathrm{II}) \mathrm{O}_{6}\right] @ \mathrm{Cu}(\mathrm{I})_{47}\left({ }^{i} \mathrm{PrC} \equiv \mathrm{C}\right)_{33}\right\} \cdot\left(\mathrm{ClO}_{4}\right)_{4}$ (3). As shown in Fig. 2a, the central $\mathrm{Cu}$ (II) cation, $\mathrm{Cu} 1$, is stabilized within the $\mathrm{Cu}(\mathrm{I})$ shell by forming $\mathrm{Cu}(\mathrm{I})-\mathrm{O}-\mathrm{Cu}(\mathrm{II})$ bonding interactions (Fig. S12 $\dagger$ ). The octahedral coordination environment of Cu1 exhibits significant Jahn-Teller distortion (Fig. S12 $\dagger$ ), where atoms $\mathrm{O} 1-\mathrm{O} 4$ are equatorial donors with $\mathrm{Cu}(\mathrm{II})-\mathrm{O}$ bond lengths of 1.940-1.957 $\mathrm{\AA}$, and $\mathrm{O} 5$ and $\mathrm{O} 6$ are axial donors with elongated distances of 2.325 and $2.635 \AA$, respectively. Bond-valence sum (BVS) calculation gives a calculated value of 2.18 for Cu1 (Table S2 $\dagger$ ). ${ }^{12}$ The + II oxidation state of $\mathrm{Cu} 1$ is further confirmed by the EPR spectrum (Fig. 2b), where it shows four-line splitting with $g_{\|}$

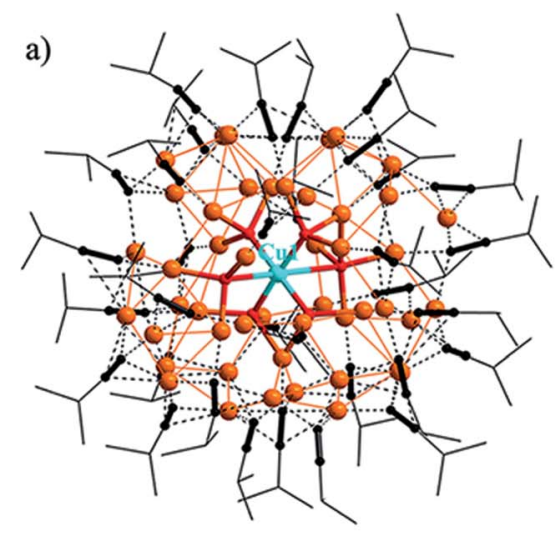

b)
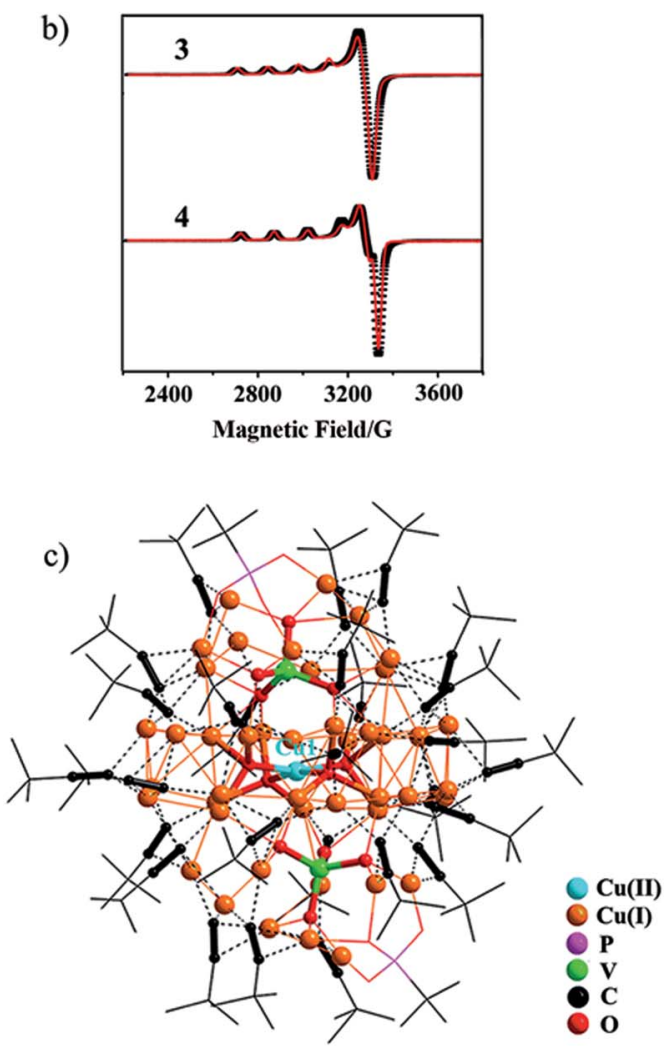

Fig. 2 Molecular structures of (a) 3; (c) 4. The $\mathrm{Cu}(॥)-\mathrm{O}-\mathrm{Cu}($ ) bonding interactions in 3 and 4 are highlighted as thicker bonds. (b) EPR spectra of 3 and 4 . Black and red lines represent the experimental and simulated EPR patterns, respectively.
(2.310) $>g_{\perp}(2.053)>g_{\mathrm{e}}(2.0023)$, and $A_{\|}=135 \mathrm{G}$ typical of $\mathrm{Cu}(\mathrm{II})$ axial signals in the $\mathrm{d}_{x^{2}-y^{2}}$ ground state, ${ }^{13}$ which is in accordance with the elongated octahedral coordination geometry of $\mathrm{Cu} 1$. This $\left\{\left[\mathrm{Cu}(\mathrm{II}) \mathrm{O}_{6}\right] @ \mathrm{Cu}(\mathrm{I})_{47}\right\}$ (C3) core is shielded by 33 peripheral ${ }^{i} \mathrm{PrC} \equiv \mathrm{C}^{-}$ligands (Fig. 2a).

In light of the alkynyl ligand effect on cluster assembly, ${ }^{i} \mathrm{PrC} \equiv \mathrm{CH}$ was replaced by ${ }^{t} \mathrm{BuC} \equiv \mathrm{CH}$ in the synthesis. Accordingly, the reaction of $\mathrm{Na}_{3} \mathrm{VO}_{4} /{ }^{t} \mathrm{BuPO}_{3} \mathrm{H}_{2}$ with $\mathrm{Cu}(0) / \mathrm{Cu}(\mathrm{II})\left(\mathrm{BF}_{4}\right)_{2} /{ }^{t} \mathrm{BuC} \equiv \mathrm{CH}$ yielded a disparate nanocluster $\left\{\left[\mathrm{Cu}(\mathrm{II}) \mathrm{O}_{4}\right] \cdot\left[\mathrm{VO}_{4}\right]_{2} @ \mathrm{Cu}(\mathrm{I})_{46}\left({ }^{t} \mathrm{BuC} \equiv \mathrm{C}\right)_{27}\left({ }^{t} \mathrm{BuPO}_{3}\right)_{2}\left(\mathrm{H}_{2} \mathrm{O}\right)\right\} \cdot\left(\mathrm{BF}_{4}\right)_{3}$. $\left(\mathrm{CH}_{2} \mathrm{Cl}_{2}\right)_{2} \cdot\left(\mathrm{Et}_{2} \mathrm{O}\right)_{2} \cdot\left(\mathrm{H}_{2} \mathrm{O}\right)(4)$. As seen in Fig. $2 \mathrm{c}, \mathrm{Cu} 1$ is also encased inside the cavity of the nanocluster that is sandwiched by two $\left[\mathrm{VO}_{4}\right]^{3-}$ anions. It exhibits a distorted squareplanar coordination geometry with $\mathrm{Cu}(\mathrm{II})-\mathrm{O}$ bond lengths of 1.913(6)-1.945(6) ^ (Fig. S12†), and BVS analysis supports its + II oxidation state (calc. 2.04 , Table S2 $\dagger$ ). In the EPR spectrum of 4 (Fig. 2b), the axial signals $g_{\|}(2.280)>g_{\perp}(2.040)>g_{\text {e }}$ (2.0023) and $A_{\|}=150 \mathrm{G}$ are in agreement with the observed coordination environment of $\mathrm{Cu} 1$. Extensive $\mathrm{Cu}(\mathrm{I})-\mathrm{O}-\mathrm{Cu}(\mathrm{II})$ connectivity (Fig. S12 $\dagger$ ) consolidates the $\left\{\left[\mathrm{Cu}(\mathrm{II}) \mathrm{O}_{4}\right] \cdot\left[\mathrm{VO}_{4}\right]_{2}\right\}$ (a) $\mathrm{Cu}(\mathrm{I})_{46}(\mathbf{C 4})$ core, which is further protected by $27{ }^{t} \mathrm{BuC} \equiv \mathrm{C}^{-}$ and $2 \mu_{4}-\kappa \mathrm{O}: \kappa \mathrm{O}^{\prime}: \kappa \mathrm{O}^{\prime}: \kappa \mathrm{O}^{\prime \prime}{ }^{t} \mathrm{BuPO}_{3}{ }^{2-}$ peripheral struts.

\section{Photophysical and optical properties}

The valence-pure 1 and 2, and mixed-valence 3 and 4 offer a new basis to explore the structure-property relationship. In this
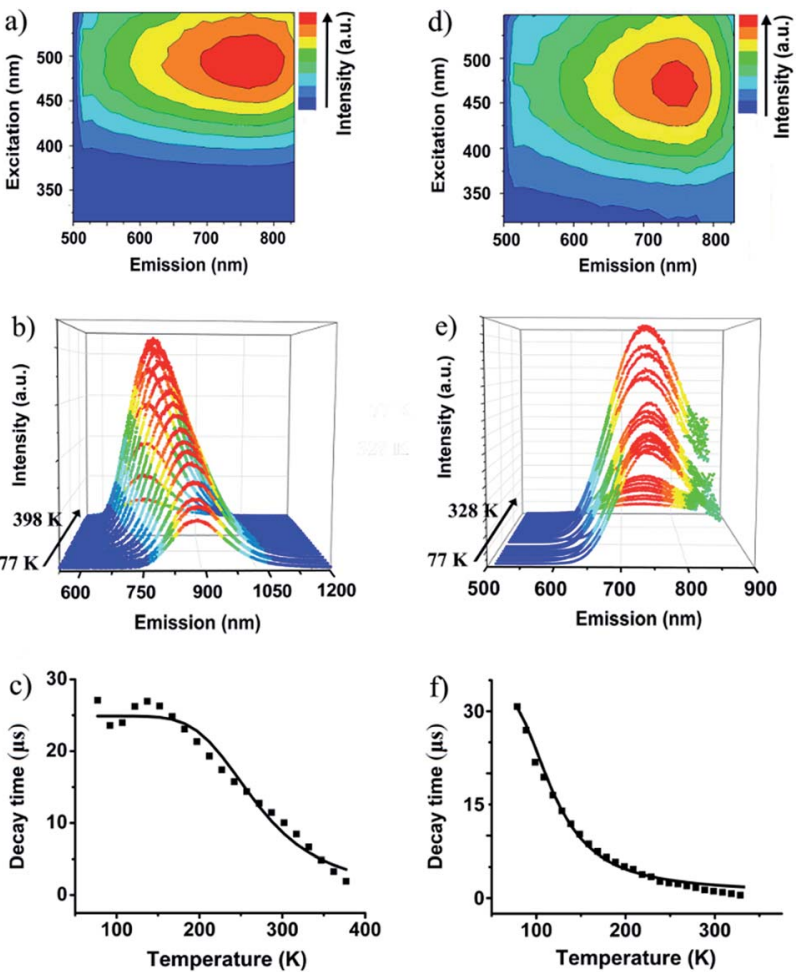

Fig. 3 3D Excitation-emission correlation spectra of (a) 1 and (d) 2 monitored in the solid state at $298 \mathrm{~K}$. Temperature-dependent emission profiles of (b) 1 and (e) 2 . Temperature-dependent emission decay time of (c) 1 and (f) 2; the solid line represents Boltzmann fitting to the experimental data. 
vein, photoluminescence as one of the most important properties was first studied. As a result, while valence-pure nanoclusters show NIR TADF, mixed-valence ones do not emit, indicating that incorporation of $\mathrm{Cu}$ (II) has quenched the photoluminescence. Fig. $3 \mathrm{a}$ and $\mathrm{d}$ show the 3D excitation-emission correlation spectra recorded for crystalline samples of $\mathbf{1}$ and $\mathbf{2}$ at $298 \mathrm{~K}$, which exhibit excitation windows with maximum wavelengths at 500 and $475 \mathrm{~nm}$, respectively. In their temperaturedependent emission profiles, while 1 largely blue-shifted upon increasing temperature, 2 only exhibited a marginal blue-shift. As shown in Fig. 3b, upon excitation at $500 \mathrm{~nm}$ at $77 \mathrm{~K}, 1$ featured a board NIR emission band centered at $871 \mathrm{~nm}$. With increasing temperature, a continuous bathochromic effect occurred to afford at $398 \mathrm{~K}$ an emission maximum at $731 \mathrm{~nm}$. The luminescence intensity grew persistently from $77 \mathrm{~K}$ to peak at $298 \mathrm{~K}$ and then started to decline, where the identifiable emission maximum at $731 \mathrm{~nm}$ was observed at $398 \mathrm{~K}$. When heated from 77 to $328 \mathrm{~K}$, the emission maximum of 2 blueshifted from 748 to $738 \mathrm{~nm}$ (Fig. 3e). In this process, the luminescence intensity increased from $77 \mathrm{~K}$ to culminate at 208 $\mathrm{K}$ and then decreased. Above $328 \mathrm{~K}$, luminescence became too weak to be identified.

The blue-shifting trend with increasing temperature is suggestive of a TADF mechanism for $\mathrm{Cu}(\mathrm{I})$ clusters 1 and $2 .{ }^{14} \mathrm{In}$ this context, the temperature-dependent emission decay time was measured (Fig. $3 \mathrm{c}$ and f), and their correlation was studied with the Boltzmann equation derived from the TADF model:

$$
\tau=\frac{\left[3+\exp \left(\Delta E\left(\mathrm{~S}_{1}-\mathrm{T}_{1}\right) / k_{\mathrm{B}} T\right)\right]}{\left[3 / \tau\left(\mathrm{T}_{1}\right)+1 / \tau\left(\mathrm{S}_{1}\right)^{*} \exp \left(\Delta E\left(\mathrm{~S}_{1}-\mathrm{T}_{1}\right) / k_{\mathrm{B}} T\right)\right]}
$$

where $\tau, \tau\left(\mathrm{S}_{1}\right), \tau\left(\mathrm{T}_{1}\right), k_{\mathrm{B}}, \Delta E\left(\mathrm{~S}_{1}-\mathrm{T}_{1}\right)$ and $\mathrm{T}$ represent the observed lifetime, singlet state decay lifetime, triplet state decay lifetime, Boltzmann constant, singlet-triplet energy separation and temperature, respectively. The crucial parameter of singlettriplet energy separation $\Delta E\left(\mathrm{~S}_{1}-\mathrm{T}_{1}\right)$ is generally required to be $<3000 \mathrm{~cm}^{-1} / 0.37 \mathrm{eV}$ for occurrence of TADF. ${ }^{14,15}$ As a result, data fitting gave $\Delta E\left(\mathrm{~S}_{1}-\mathrm{T}_{1}\right)=1200 \mathrm{~cm}^{-1} / 0.15 \mathrm{eV}, \tau\left(\mathrm{T}_{1}\right)=25 \mu \mathrm{s}$ and $\tau\left(\mathrm{S}_{1}\right)=14 \mathrm{~ns}$ for 1 . For 2 , values of $\Delta E\left(\mathrm{~S}_{1}-\mathrm{T}_{1}\right)=380 \mathrm{~cm}^{-1} / 0.047$ $\mathrm{eV}, \tau\left(\mathrm{T}_{1}\right)=33.5 \mu \mathrm{s}$ and $\tau\left(\mathrm{S}_{1}\right)=115 \mathrm{~ns}$ were extracted. These values demonstrate that TADF occurred with reverse intersystem crossing (RISC) from the triplet state $T_{1}$ to the singlet manifold $S_{1}$. Furthermore, variation of emission intensity as a function of temperature also substantiates an equilibrium between the $T_{1}$ state and $S_{1}$ state. ${ }^{16}$ As mentioned above, the emission intensity shows a bell shape from low to high temperature (Fig. $3 \mathrm{~b}$ and e). This is due to up-conversion of the $\mathrm{T}_{1}$ to $\mathrm{S}_{1}$ state upon increasing the temperature (increasing intensity), followed by thermal vibration to depopulate the excited state at higher temperature (decreasing intensity). It is worth noting that $\mathbf{1}$ and $\mathbf{2}$ represent the first examples of highnuclearity metal clusters displaying NIR TADF, and this implies that the photoluminescence attributes of $\mathrm{Cu}(\mathrm{I})$ alkynyl nanoclusters are favorable.

DFT calculations were performed with the Vienna $A b$ initio Simulation Package (VASP) $)^{17}$ to gain insight into the photophysical properties of $\mathbf{1}$ and 2, where their whole molecular

structures remained intact. The Perdew-Burke-Ernzerhof (PBE) exchange-correlation functional and projector augmented wave (PAW) method were employed with an energy cutoff of 500.0 eV.$^{18}$ For computational efficiency, a single nanocluster of 1 and 2 was extracted and padded with $10 \AA$ in $x, y$, and $z$ directions, and the gamma point was used to sample the Brillouin zone. The optimized geometries of the ground state of $\mathbf{1}$ and $\mathbf{2}$ are comparable to those determined by X-ray crystallographic analysis. For example, the computed structure of 1 gave bond lengths of $\mathrm{Cu} 12-\mathrm{O} 12.348$ and $\mathrm{Cu} 12-\mathrm{O} 22.118 \AA$, which are close to the respective values of 2.379 and $2.169 \AA$ in the crystal structure. The highest occupied molecular orbital (HOMO) and lowest unoccupied molecular orbital (LUMO) of $\mathbf{1}$ and $\mathbf{2}$ are shown in Fig. 4. For 1, the HOMO is predominately distributed over the nitrate oxygen atoms and their coordinated $\mathrm{Cu}(\mathrm{I})$ atoms, whereas the LUMO resides on the remaining $\mathrm{Cu}(\mathrm{I})$ atoms with some population on the ${ }^{t} \mathrm{BuC} \equiv \mathrm{C}^{-}$ligands. For 2 , the HOMO is dominated by the sulfate oxygen atoms and their coordinated $\mathrm{Cu}(\mathrm{I})$ atoms and ${ }^{t} \mathrm{BuC} \equiv \mathrm{C}^{-}$ligands, and the LUMO is contributed by $\mathrm{Cu}(\mathrm{I})$ atoms and ${ }^{t} \mathrm{BuC} \equiv \mathrm{C}^{-}$ligands. Thus the emissions of $\mathbf{1}$ and $\mathbf{2}$ originating from LUMO to HOMO charge transfer mainly involve a mixed ${ }^{t} \mathrm{BuC} \equiv \mathrm{C}^{-} \rightarrow \mathrm{Cu}(\mathrm{I})$ LMCT and cluster-centered transition. This result is in agreement with that of $\left[\mathrm{Cu}(\mathrm{I})_{15}\left({ }^{t} \mathrm{BuC} \equiv \mathrm{C}\right)_{10}\left(\mathrm{CF}_{3} \mathrm{COO}\right)_{5}\right] \cdot{ }^{t} \mathrm{BuC} \equiv \mathrm{CH}$ reported by Sun. ${ }^{19}$

To contextualize the quenching effect of $\mathrm{Cu}$ (II) on photoluminescence properties, we compared the optical properties of 1-2 with 3-4. Fig. 5 shows the UV-Vis-NIR spectra measured in the solid state. While 1 and 2 show no indication of NIR absorption, 3 and $\mathbf{4}$ exhibit prominent bands in the NIR region 700-1200 nm, which evidently stem from incorporation of $\mathrm{Cu}$ (II). According to the DFT calculation and reported metal alkynyl clusters, the visible-light absorption in $300-600 \mathrm{~nm}$ for 1-4 is attributed to various charge transfer transitions including $\pi \rightarrow \pi^{*}$ acetylide, cluster-centered, MLCT and LMCT interactions. ${ }^{19 a, 20}$ In contrast, the NIR absorption of 3 and 4 is assigned to IVCT from $\mathrm{Cu}(\mathrm{I})\left(3 \mathrm{~d}^{10}\right)$ to $\mathrm{Cu}(\mathrm{II})\left(3 \mathrm{~d}^{9}\right)$. Such IVCT was achieved by the $\mathrm{Cu}(\mathrm{I})-\mathrm{O}-\mathrm{Cu}(\mathrm{II})$ linkage as described above. ${ }^{20}$ The fact that $\mathbf{3}$ and $\mathbf{4}$ do not emit also provides spectral evidence for

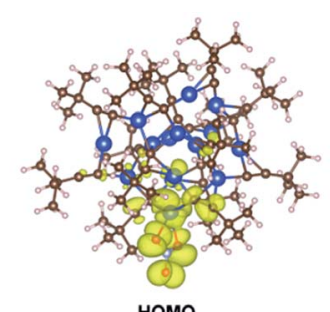

номо

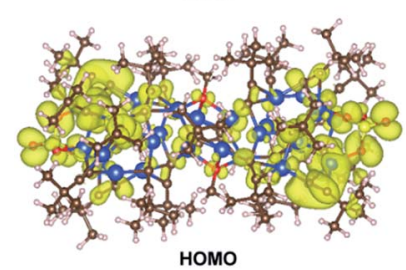

Fig. 4 Frontier molecular orbitals of 1 (upper) and 2 (lower) at the ground state. 
a charge-transfer quenching mechanism, that is, the characteristic photoluminescence of $\mathbf{3}$ and $\mathbf{4}$ originating from the alkynyl $\rightarrow \mathrm{Cu}(\mathrm{I})$ LMCT and cluster-centered transition was switched off by the subsequent $\mathrm{Cu}(\mathrm{I}) \rightarrow \mathrm{Cu}(\mathrm{II})$ IVCT transition. ${ }^{21}$

\section{Dielectric and electrical properties}

The divergent photophysical properties of 1-2 from 3-4 demonstrate that their metal cores tailor the materials' bulk behavior. This prompts us to further explore their dielectric and electrical properties, which have been less studied in metal nanoclusters owing to their instability in the fabrication of high-quality thin films. ${ }^{22}$ In this vein, bulk crystalline samples of 1-4 were each prepared as a pellet and sandwiched between $\mathrm{Cu}$ and $\mathrm{Al}$ electrodes to fabricate an electronic device for measurements (Fig. 6a). As shown in Fig. 6b, 1 and 2 display frequency-independent dielectric behavior with a dielectric constant of about 5.0, which corresponds to a low-dielectric state. By contrast, drastic response to frequency was detected from $10^{3}$ and $10^{2} \mathrm{~Hz}$ for 3 and 4 , which gave at $20 \mathrm{~Hz}$ high dielectric constants of 3800 and 1500, respectively. For reference, $\quad\left[\mathrm{Cu}(\mathrm{I})_{17}\left({ }^{t} \mathrm{BuC} \equiv \mathrm{C}\right)_{16} \mathrm{MeOH}\right] \cdot \mathrm{BF}_{4}$ with a cation-anion structure showed similar dielectric behavior to neutral nanoclusters 1 and 2 (Fig. $\mathrm{S} 11^{\dagger}$ ). This excludes the possibility that the high-dielectric state of $\mathbf{3}$ and $\mathbf{4}$ originates from cation/anion movement under an applied electric field. Instead, it is attributed to interfacial polarization dictated by the presence/distribution of $\mathrm{Cu}(\mathrm{II})$ cations and $\mathrm{O}^{2-}$ anions with large dipole moments.

The temperature-dependent electrical conductivities of 1-4 were measured using a two-probe current-voltage $(I-V)$ technique. At ambient temperature, 1 and 2 show low conductivities of $3.19 \times 10^{-11}$ and $6.09 \times 10^{-11} \mathrm{~S} \mathrm{~m}^{-1}$, which upon increasing the temperature to $100{ }^{\circ} \mathrm{C}$ increased to $2.57 \times 10^{-8}$ and $2.29 \times$ $10^{-9} \mathrm{~S} \mathrm{~m}^{-1}$, respectively. The $I-V$ curves show a linear characteristic in the measured temperature range (Fig. 6c). As seen in Fig. 6d, the corresponding Arrhenius fit to data in the linear regime provides activation energies of $1.06 \mathrm{eV}$ for 1 and $0.97 \mathrm{eV}$ for 2 , suggesting that both are electrical insulators. In contrast, the ambient temperature conductivities of $\mathbf{3}$ and $\mathbf{4}$ are significantly higher at $1.01 \times 10^{-6}$ and $1.24 \times 10^{-8} \mathrm{~S} \mathrm{~m}^{-1}$ and enhanced over a temperature range of $80{ }^{\circ} \mathrm{C}$ to attain $2.33 \times$

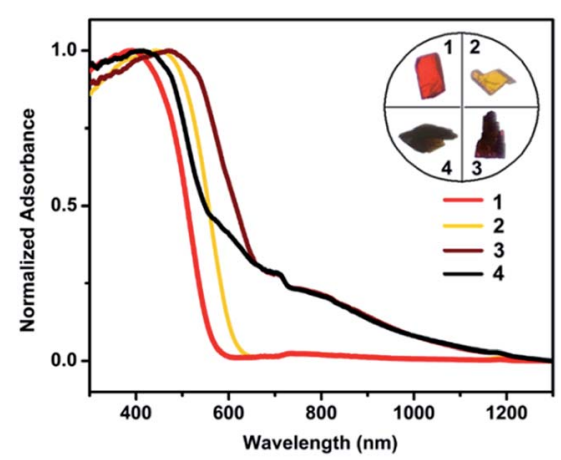

Fig. 5 UV-Vis-NIR diffuse reflectance spectra of 1-4 measured in the solid state. Inset: appearance of single crystals under ambient light.
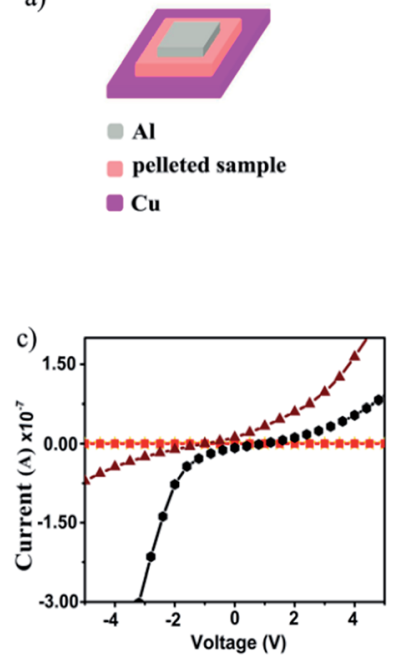
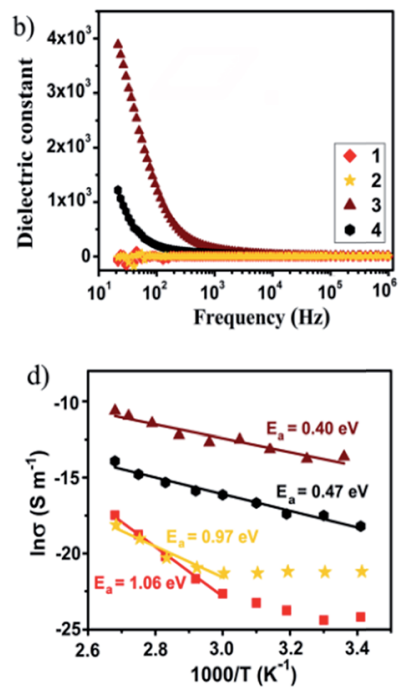

Fig. 6 (a) Fabrication of an electronic device for dielectric and electrical measurements. (b) Frequency-dependent dielectric constants of 1-4 recorded at room temperature. (c) Current-voltage curves recorded at room temperature. (d) Temperature-dependent electrical conductivity; straight lines represent Arrhenius fitting to the experimental data.

$10^{-5}$ and $9.04 \times 10^{-7} \mathrm{~S} \mathrm{~m}^{-1}$, respectively. As such, 3 and 4 show two to four orders of magnitude increased ambient-temperature conductivities over $\mathbf{1}$ and 2 . The logarithm of conductivity and inverse temperature displays a linear relationship, which indicates that $\mathbf{3}$ and $\mathbf{4}$ are thermally activated semiconductors. The activation energy was fitted to be $0.40 \mathrm{eV}$ for 3 and $0.47 \mathrm{eV}$ for 4 . The electrical conductivities of $\mathbf{3}$ and $\mathbf{4}$ are comparable to those of semiconductive $\mathrm{Cu}$ (II) materials with moderate conductivity. ${ }^{23}$ Their enhanced electrical conductivities are likely due to interstitial incorporation of a $\mathrm{Cu}$ (II) cation as the electron acceptor to trigger IVCT that follows LMCT to facilitate charge mobility, ${ }^{24}$ where the $\mathrm{Cu}(\mathrm{II})$ cation should be chemically stabilized by ligand oxygen atoms within the $\mathrm{Cu}(\mathrm{I})$ shell. These results suggest that the electrical nature of $\mathrm{Cu}(\mathrm{I})$ nanoclusters can be modified by incorporating a trace amount of $\mathrm{Cu}$ (II) as the dopant, which may facilitate the search for suitable metal nanoclusters as new semiconducting materials.

\section{Conclusions}

In summary, we have prepared mixed-valence $\mathrm{Cu}(\mathrm{II}) / \mathrm{Cu}(\mathrm{I})$ nanoclusters via a vanadate-assisted oxidative procedure for comparison with related valence-pure $\mathrm{Cu}(\mathrm{I})$ nanoclusters. The charge-transfer processes occurring within these two types of nanoclusters dominate their photophysical, dielectric and electrical properties. Particularly, while the valence-pure nanoclusters exhibit near-infrared thermally activated delayed fluorescence, the mixed-valence ones display semiconductivity. These results not only demonstrate the feasibility to modify the metal core to engender distinct desirable properties, but also facilitate rationalization of the structure-property relationship for future development of function-specific metal nanoclusters. 


\section{Conflicts of interest}

There are no conflicts to declare.

\section{Acknowledgements}

This work is dedicated to the memory of Prof. George A. Jeffrey (1915-2000), Founding Head of Department of Crystallography at the University of Pittsburgh. We gratefully acknowledge financial support by the Wei Lun Foundation and Faculty of Engineering Direct Grant by the Chinese University of Hong Kong, and a Postdoctoral Fellowship to L. L.-M. Zhang by the Chinese University of Hong Kong.

\section{Notes and references}

1 (a) Z. Lei, X.-K. Wan, S.-F. Yuan, Z.-J. Guan and Q.-M. Wang, Acc. Chem. Res., 2018, 51, 2465; (b) R. S. Dhayal, W. E. van Zyl and C. W. Liu, Acc. Chem. Res., 2016, 49, 86; (c) Z. B. Gan, N. Xia and Z. K. Wu, Acc. Chem. Res., 2018, 51, 2774; (d) Q.-M. Wang, Y.-M. Lin and K.-G. Liu, Acc. Chem. Res., 2015, 48, 1570; (e) Q. Li, M. Zhou, W. Y. So, J. C. Huang, M. X. Li, D. R. Kauffman, M. Cotlet, T. Higaki, L. A. Peteanu, Z. Z. Shao and R. Jin, J. Am. Chem. Soc., 2019, 141, 5314; $(f)$ X. Kang, S. X. Wang, Y. B. Song, S. Jin, G. D. Sun, H. Z. Yu and M. Z. Zhu, Angew. Chem., Int. Ed., 2016, 55, 3611; $(g)$ T. A. Nguyen, Z. R. Jones, B. R. Goldsmith, W. R. Buratto, G. Wu, S. L. Scott and T. W. Hayton, J. Am. Chem. Soc., 2015, 137, 13319.

2 (a) X. Liu and D. Astruc, Coord. Chem. Rev., 2018, 359, 112; (b) X. Kang and M. Zhu, Chem. Soc. Rev., 2019, 48, 2422; (c) V. W.-W. Yam and K. K.-W. Lo, Chem. Soc. Rev., 1999, 28, 323; (d) X. Yuan, Z. Luo, Y. Yu, Q. Yao and J. Xie, Chem.Asian J., 2013, 8, 858; (e) Z.-H. Chen, L.-Y. Zhang and Z.-N. Chen, Organometallics, 2012, 31, 256; (f) J.-W. Liu, L. Feng, H.-F. Su, Z. Wang, Q.-Q. Zhao, X.-P. Wang, C.-H. Tung, D. Sun and L.-S. Zheng, J. Am. Chem. Soc., 2018, 140, 1600; (g) Z. Wang, H.-F. Su, C.-H. Tung, D. Sun and L.-S. Zheng, Nat. Commun., 2018, 9, 4407; (h) S.-S. Zhang, H.-F. Su, G.-L. Zhuang, X.-P. Wang, C.-H. Tung, D. Sun and L.-S. Zheng, Chem. Commun., 2018, 54, 11905; (i) Z. Wang, H.-F. Su, Y.-Z. Tan, S. Schein, S.-C. Lin, W. Liu, S.-A. Wang, W.-G. Wang, C.-H. Tung, D. Sun and L.-S. Zheng, Proc. Natl. Acad. Sci. U. S. A., 2017, 114, 12132.

3 (a) R. Jin, Nanoscale, 2015, 7, 1549; (b) M. Zhu, C. M. Aikens, F. J. Hollander, G. C. Schatz and R. Jin, J. Am. Chem. Soc., 2008, 130, 5883; (c) W.-H. Fang, L. Zhang and J. Zhang, J. Am. Chem. Soc., 2016, 138, 7480; (d) H. N. Miras, J. Yan, D.-L. Long and L. Cronin, Chem. Soc. Rev., 2012, 41, 7403; (e) D.-L. Long, E. Burkholdera and L. Cronin, Chem. Soc. Rev., 2007, 36, 105; (f) K.-G. Liu, S.-K. Chen, Y.-M. Lin and Q.-M. Wang, Chem. Commun., 2015, 51, 9896.

4 (a) S. Hossain, Y. Niihori, L. V. Nair, B. Kumar, W. Kurashige and Y. Negishi, Acc. Chem. Res., 2018, 51, 3114; (b) Y. Negishi, W. Kurashige, Y. Niihori and K. Nobusada, Phys. Chem. Chem. Phys., 2013, 15, 18736; (c) S. Wang, Y. Song, S. Jin,
X. Liu, J. Zhang, Y. Pei, X. Meng, M. Chen, P. Li and M. Zhu, J. Am. Chem. Soc., 2015, 137, 4018; (d) G. Soldan, M. A. Aljuhani, M. S. Bootharaju, L. G. AbdulHalim, M. R. Parida, A.-H. Emwas, O. F. Mohammed and O. M. Bakr, Angew. Chem., Int. Ed., 2016, 55, 5749; (e) A. Ghosh, O. F. Mohammed and O. M. Bakr, Acc. Chem. Res., 2018, 51, 3094; (f) Y. Wang, H. Su, L. Ren, S. Malola, S. Lin, B. K. Teo, H. Häkkinen and N. Zheng, Angew. Chem., Int. Ed., 2016, 55, 15152; (g) R. P. B. Silalahi, K. K. Chakrahari, J.-H. Liao, S. Kahlal, Y.-C. Liu, M.-H. Chiang, J.-Y. Saillard and C. W. Liu, Chem.-Asian J., 2018, 13, 500; (h) H. Qian, D. Jiang, G. Li, C. Gayathri, A. Das, R. R. Gil and R. Jin, J. Am. Chem. Soc., 2012, 134, 16159.

5 (a) F. Olbrich, J. Kopf and E. Weiss, Angew. Chem., Int. Ed., 1993, 32, 1077; (b) T. C. Higgs, P. J. Bailey, S. Parsons and P. A. Tasker, Angew. Chem., Int. Ed., 2002, 41, 3038; (c) S. S. Y. Chui, M. F. Y. Ng and C.-M. Che, Chem.-Eur. J., 2005, 11, 1739; (d) X. Y. Chang, K. H. Low, J. Y. Wang, J. S. Huang and C.-M. Che, Angew. Chem., Int. Ed., 2016, 55, 10312; (e) G.-C. Kuang, P. M. Guha, W. S. Brotherton, J. T. Simmons, L. A. Stankee, B. T. Nguyen, R. J. Clark and L. Zhu, J. Am. Chem. Soc., 2011, 133, 13984; (f) H. Lang, A. Jakob and B. Milde, Organometallics, 2012, 31, 7661.

6 A. W. Cook, Z. R. Jones, G. Wu, S. L. Scott and T. W. Hayton, J. Am. Chem. Soc., 2018, 140, 394.

7 P. Yuan, R. H. Chen, X. M. Zhang, F. J. Chen, J. Z. Yan, C. F. Sun, D. H. Ou, J. Peng, S. C. Lin, Z. C. Tang, B. K. Teo, L. S. Zheng and N. F. Zheng, Angew. Chem., Int. Ed., 2019, 58, 835.

8 (a) L.-M. Zhang and T. C. W. Mak, J. Am. Chem. Soc., 2016, 138, 2909; (b) L. L.-M. Zhang and T. C. W. Mak, Angew. Chem., Int. Ed., 2017, 56, 16228.

9 (a) I. Chakraborty and T. Pradeep, Chem. Rev., 2017, 117, 8208; (b) B. Nieto-Ortega and T. Bürgi, Acc. Chem. Res., 2018, 51, 2811; (c) K. Kwak and D. Lee, Acc. Chem. Res., 2019, 52, 12; (d) R. Jin, C. Zeng, M. Zhou and Y. Chen, Chem. Rev., 2016, 116, 10346.

10 Y.-P. Xie, J.-B. Wen, C.-W. Pan, G.-X. Duan, L.-Y. Li and X. Lu, Cryst. Growth Des., 2019, DOI: 10.1021/acs.cgd.9b00803.

11 (a) Y.-P. Xie and T. C. W. Mak, J. Am. Chem. Soc., 2011, 133, 3760; (b) Y.-P. Xie and T. C. W. Mak, Angew. Chem., Int. Ed., 2012, 51, 8783; (c) Y.-P. Xie, J.-L. Jin, X. Lu and T. C. W. Mak, Angew. Chem., Int. Ed., 2015, 54, 15176; (d) Y.-P. Xie and T. C. W. Mak, Chem. Commun., 2012, 48, 1123; (e) G.-X. Duan, Y.-P. Xie, J.-L. Jin, L.-P. Bao, X. Lu and T. C. W. Mak, Chem.-Eur. J., 2018, 24, 6662; (f) G.-G. Gao, P.-S. Cheng and T. C. W. Mak, J. Am. Chem. Soc., 2009, 131, 18257; (g) H. Liu, C.-Y. Song, R.-W. Huang, Y. Zhang, H. Xu, M.-J. Li, S.-Q. Zang and G.-G. Gao, Angew. Chem., Int. Ed., 2016, 55, 3699.

12 I. D. Brown and D. Altermatt, Acta Crystallogr., Sect. B: Struct. Sci., Cryst. Eng. Mater., 1985, 41, 244.

13 (a) D. Armentano, T. F. Mastropietro, M. Julve, R. Rossi, P. Rossi and G. De Munno, J. Am. Chem. Soc., 2007, 129, 2740; (b) V. Shivaiah and S. K. Das, Angew. Chem., Int. Ed., 2006, 45, 245; (c) E. Faggi, R. Gavara, M. Bolte, L. Fajarí, 
L. Juliá, L. Rodríguez and I. Alfonso, Dalton Trans., 2015, 44, 12700.

14 S. Evariste, A. M. Khalil, M. E. Moussa, A. K.-W. Chan, E. Y.-H. Hong, H.-L. Wong, B. L. Guennic, G. Calvez, K. Costuas, V. W.-W. Yam and C. Lescop, J. Am. Chem. Soc., 2018, 140, 12521.

15 (a) T. Sajoto, P. I. Djurovich, A. B. Tamayo, J. Oxgaard, W. A. Goddard and M. E. Thompson, J. Am. Chem. Soc., 2009, 131, 9813; (b) T. Hofbeck, U. Monkowius and H. Yersin, J. Am. Chem. Soc., 2015, 137, 399; (c) M. J. Leitl, V. A. Krylova, P. I. Djurovich, M. E. Thompson and H. Yersin, J. Am. Chem. Soc., 2014, 136, 16032; (d) R. Czerwieniec, M. J. Leitl, H. H. H. Homeier and H. Yersin, Coord. Chem. Rev., 2016, 325, 2; (e) T. J. Feuerstein, B. Goswami, P. Rauthe, R. Köppe, S. Lebedkin, M. M. Kappesbc and P. W. Roesky, Chem. Sci., 2019, 10, 4742.

16 G. Li, R. S. Nobuyasu, B. Zhang, Y. Geng, B. Yao, Z. Xie, D. Zhu, G. Shan, W. Che, L. Yan, Z. Su, F. B. Dias and M. R. Bryce, Chem.-Eur. J., 2017, 23, 11761.

17 (a) G. Kresse, J. Non-Cryst. Solids, 1995, 192-193, 222; (b) G. Kresse and J. Hafner, Phys. Rev. B: Condens. Matter Mater. Phys., 1994, 49, 14251; (c) G. Kresse and J. Furthmuller, Comput. Mater. Sci., 1996, 6, 15; (d) G. Kresse and J. Furthmuller, Phys. Rev. B: Condens. Matter Mater. Phys., 1996, 54, 11169.

18 (a) J. P. Perdew, K. Burke and M. Ernzerhof, Phys. Rev. Lett., 1996, 77, 3865; (b) P. E. Blöchl, Phys. Rev. B: Condens. Matter Mater. Phys., 1994, 50, 17953.

19 (a) H.-Y. Zhuo, H.-F. Su, Z.-Z. Cao, W. Liu, S.-A. Wang, L. Feng, G.-L. Zhuang, S.-C. Lin, M. Kurmoo, C.-H. Tung, D. Sun and L.-S. Zheng, Chem.-Eur. J., 2016, 22, 17619; (b) H.-Y. Zhuo, A.-Y. Hu, L. Feng, Q.-Y. Liu, X.-P. Wang and D. Sun, J. Cluster Sci., 2018, 29, 1017.
20 (a) C. Chan, K. Cheung, W. H. Lam, E. C. Cheng, N. Zhu, S. W. Choi and V. W.-W. Yam, Chem.-Asian J., 2006, 1, 273; (b) W.-Y. Lo, C.-H. Lam, V. W.-W. Yam, N. Zhu, K.-K. Cheung, S. Fathallah, S. Messaoudi, B. L. Guennic, S. Kahlal and J.-F. Halet, J. Am. Chem. Soc., 2004, 126, 7300; (c) G. F. Manbeck, W. W. Brennessel, R. A. Stockland and R. Eisenberg, J. Am. Chem. Soc., 2010, 132, 12307; (d) S. Ibáñez, M. Poyatos and E. Peris, Angew. Chem., Int. Ed., 2018, 57, 16816.

21 (a) S. Chen, W.-H. Fang, L. Zhang and J. Zhang, Angew. Chem., Int. Ed., 2018, 57, 11252; (b) X. Ma, C.-S. Lin, X.-Q. Zhu, S.-M. Hu, T.-L. Sheng and X.-T. Wu, Angew. Chem., Int. Ed., 2017, 56, 1605; (c) R.-W. Huang, Q.-Q. Xu, H.-L. Lu, X.-K. Guo, S.-Q. Zang, G.-G. Gao, M.-S. Tang and T. C. W. Mak, Nanoscale, 2015, 7, 7151; (d) Y. Xiao and Q.-M. Wang, Chem.-Eur. J., 2012, 18, 11184.

22 (a) M. Galchenko, A. Black, L. Heymann and C. Klinke, Adv. Mater., 2019, 31, 1900684; (b) F. A. Brede, J. Heine, G. Sextl and K. Müller-Buschbaum, Chem.-Eur. J., 2016, 22, 2708.

23 (a) J. Park, A. C. Hinckley, Z. H. Huang, D. W. Feng, A. A. Yakovenko, M. Lee, S. C. Chen, X. D. Zou and Z. N. Bao, J. Am. Chem. Soc., 2018, 140, 14533; (b) H. Nagatomi, N. Yanai, T. Yamada, K. Shiraishi and N. Kimizuka, Chem.-Eur. J., 2018, 24, 1806; (c) F. Yu, J. Li, Z.-H. Cao, M. Kurmoo and J.-L. Zuo, Inorg. Chem., 2018, 57, 3443.

24 (a) J. A. DeGayner, I.-R. Jeon, L. Sun, M. Dincă and T. D. Harris, J. Am. Chem. Soc., 2017, 139, 4175; (b) I.-R. Jeon, L. Sun, B. Negru, R. P. V. Duyne, M. Dinca and T. D. Harris, J. Am. Chem. Soc., 2016, 138, 6583; (c) L. J. Liu, J. A. DeGayner, L. Sun, D. Z. Zee and T. D. Harris, Chem. Sci., 2019, 10, 4652. 